BOOKS

\title{
Photographs of dissection: from memento to the macabre
}

Previously published at www.cmaj.ca

Dissection: Photographs of a Rite of

Passage in American Medicine: 1880-1930 John Harley Warner and James M.

Edmonson

Blast Books; 2009.

$\mathrm{N}$ ineteenth and early 20th century literature on dissectors and dissection was generated as a result of the controversy that ensued when bodies went missing from their graves, medical students were suspected and local populace rioted. ${ }^{1,2}$ Much of it is refractory writing in the form of journal articles, editorials and anecdotes published by a medical elite at a time when the ranks of medical students swelled and anatomic material became scarce.

An iconography of dissection photographs has emerged to supplement this colourful history - the collaborative vision of Jim Edmonson, the curator of the Dittrick Medical History Center and Museum at Case Western Reserve University, Cleveland, Ohio, and medical historian John Harley Warner of Yale University School of Medicine, New Haven, Connecticut. Their richly illustrated large-format monograph brings together postcards, cabinet cards, stereographs and scrapbook album pages drawn from a number of sources, including several important pieces from the Women in Medicine collection at Drexel. More than half of the images - some of which are quite extraordinary - are drawn from the nearly 200 pieces that $\&$ Edmonson procured for the Dittrick Museum.

The majority of the photographs are group portraits of student anatomists standing behind their cadavers with anatomy books propped open and a display of period instruments such as

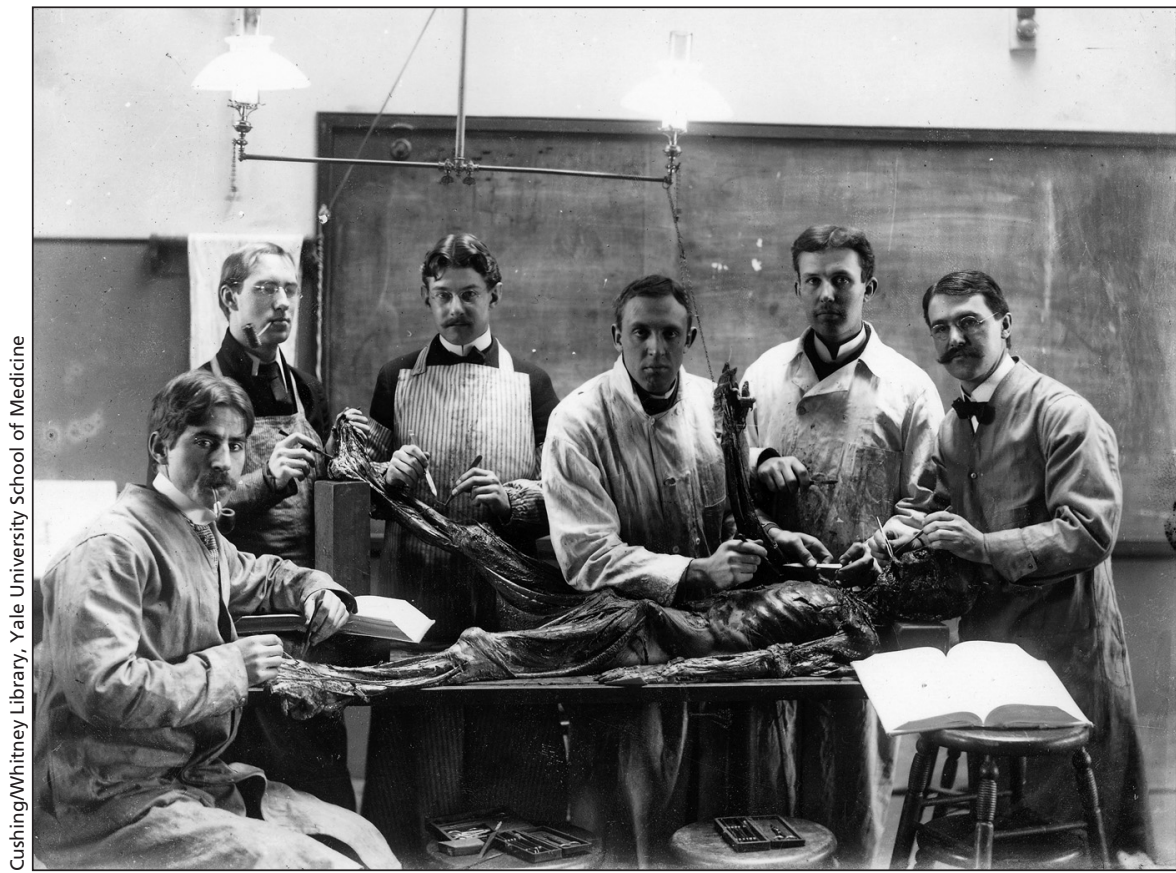

This circa 1910 dissection scene at Yale University, New Haven, Connecticut, is a departure from the usual ghoulish depiction.

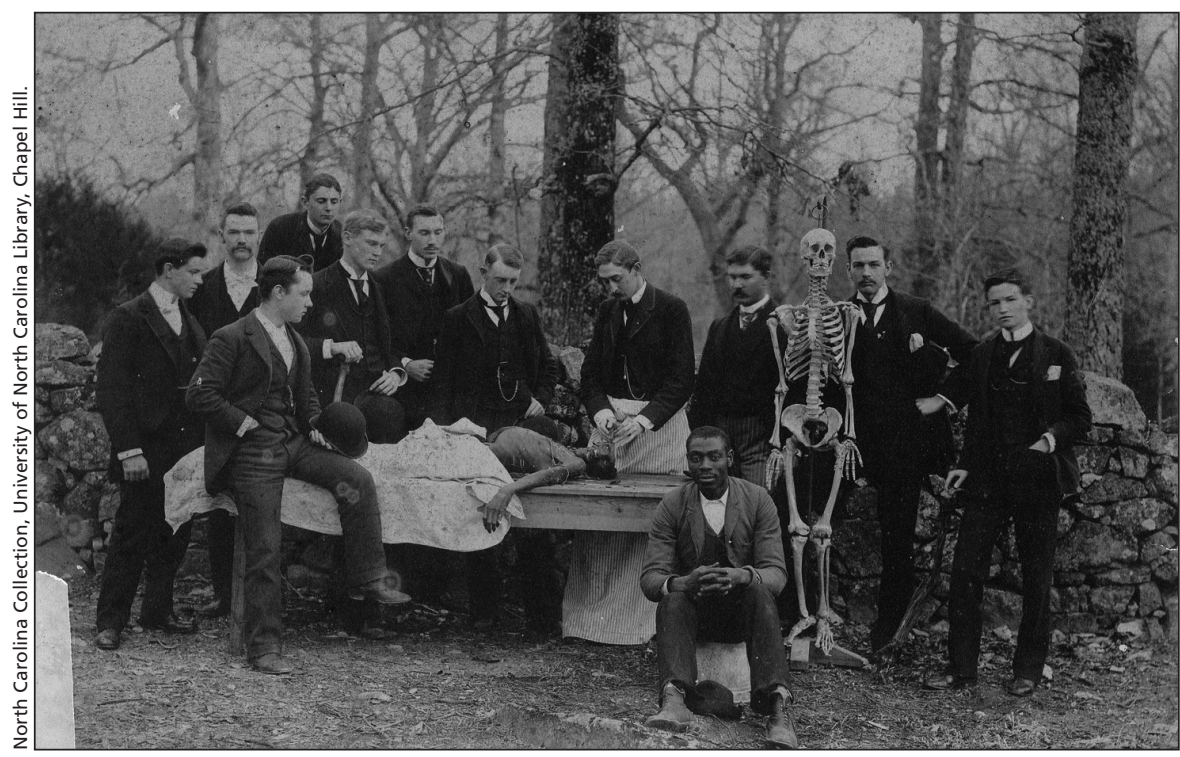

In this circa 1890 staged dissection scene, medical students at the University of North Carolina, Raleigh, included all the key elements of the genre: cadaver, table, dissectors and skeleton, as well as the janitor or porter. 


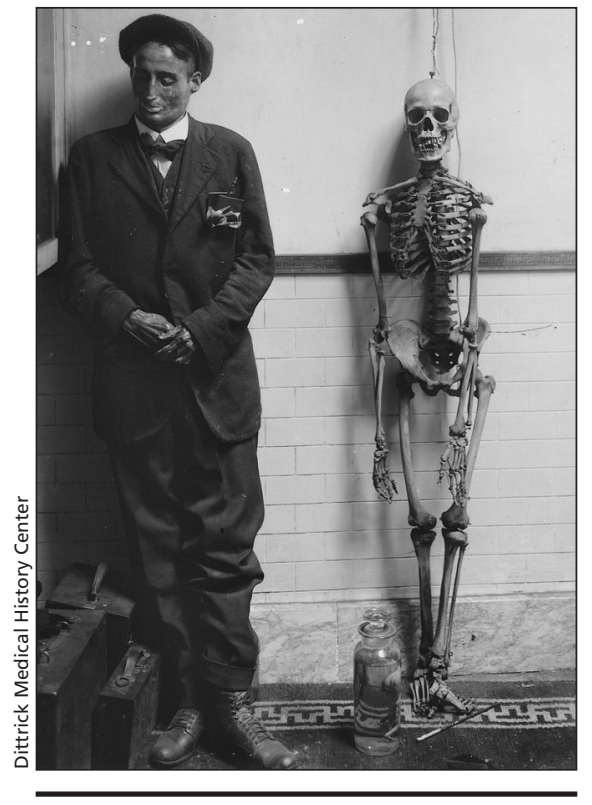

This undated photograph of a fully dressed cadaver perched next to a skeleton, with a fluid-preserved fetal specimen at their feet, is one of many attempts at humour.

scalpels, hooks, tension saws and, in one picture, an iron calotte clamp. Other recurring elements of the genre include skull and bone graphics painted onto caps or aprons and inscriptions chalked on the dissection tables pronouncing, "A vulture's love," or "He lived for others, he died for us."

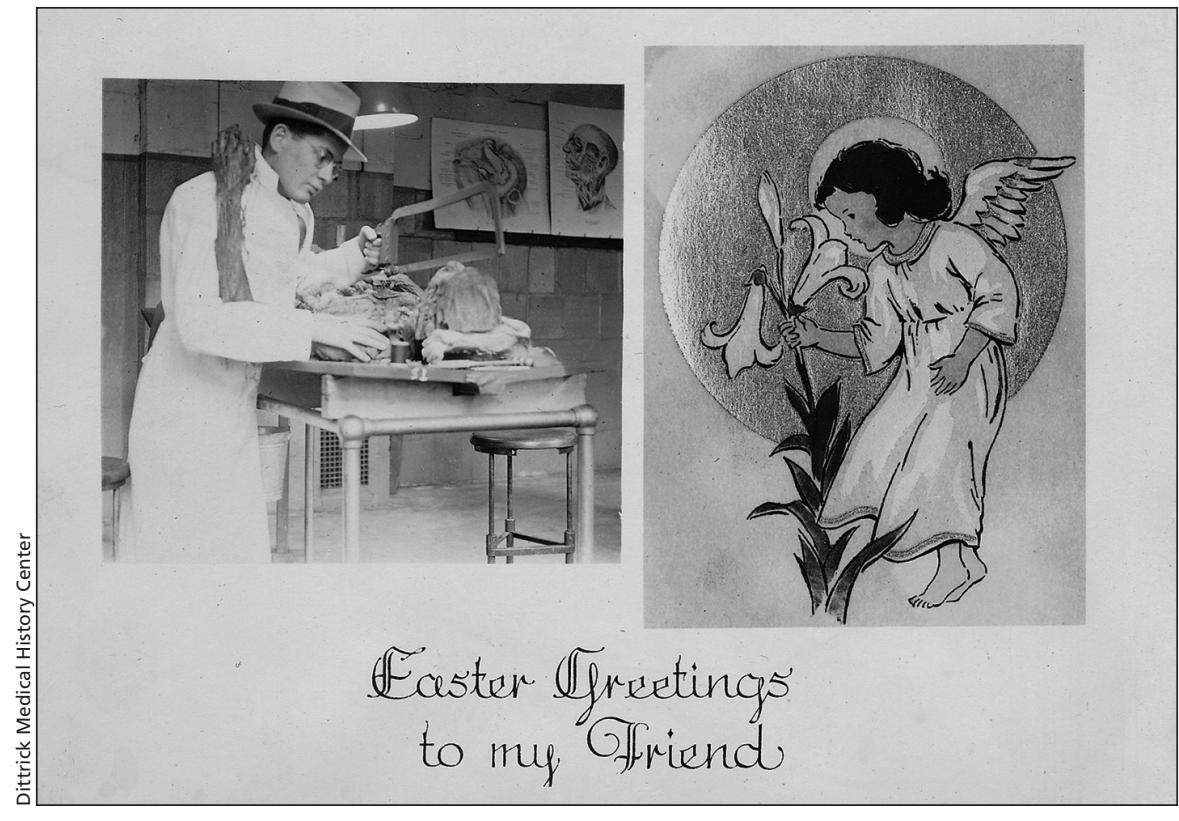

Although dissection room photographs were usually a private professional memento, sometimes they were made into greeting cards, particularly at Easter, perhaps due to the obvious association with death and resurrection. This card, circa 1920, is from an unknown school in the United States.

steady stream of anatomic material. Less well documented are the effects these dehumanizing strategies had on the dissectors themselves.

The Edmonson \& Warner iconography presents compelling evidence of the socialization that set dissectors apart from the rest of society at the

\section{Less well documented are the effects these dehumanizing strategies had on the dissectors themselves.}

This is clumsy student work and the cadavers all look like the remaindered manikins from a fright fest — save for a beautiful preparation by the circa 1910 Yale team.

There is no undoing the psychic transgressions committed in the carnal chop shop of gross anatomy. A medical student suppresses his or her horror of the cadaver with the help of long standing traditions and professional absolutism that rebar a medical education. Nineteenth century strategies for the suppression of dissection horror were primarily directed against the poor and disenfranchised in order to maintain the time. Usually, this took the form of collegiate bravado and pranks. According to Joseph Marshall Flint (1872-1944) during anatomic studies at Johns Hopkins University, Baltimore, Maryland:

Hats were worn; students dressed in outlandish costumes. Smoking was generally permitted, and boisterous conduct accompanied by the throwing of material, were not infrequent occurrences. ${ }^{4}$

Why else was a cadaver dressed in formal attire and propped against a wall if not for a group lark or hazing? Next to the corpse stands a female skeleton with a bottled fetus and a bloodied rod at her feet - the scene makes for a twisted hilarity on medical malpractice. The iconography also provides several examples of staged role reversals whereby a student climbs onto the dissection table and a cadaver plays the part of dissector. But the humour is layered with the mental sacrifices made for the sake of acquiring a medical education.

Fortunately, student anatomists today are made aware of the dangers of dehumanizing the corpse and this book will be used as a teaching tool for this purpose.

\section{Mark Rowley BFA}

Artist

Brooklyn, US

Mark Rowley has been compiling a bibliography of pre-1890 medical photography for the past six years.

\section{REFERENCES}

1. Waite FC. Grave robbing in New England. Bull Med Libr Assoc 1945;33:272-94.

2. Sappol M. A traffic of dead bodies. Princeton (NJ): Princeton University Press; 2002.

3. Richardson R. Death, dissection and the destitute. New York (NY): Routledge \& Kegan Paul; 1987.

4. Bardeen CR. Anatomy in America. Bull. U. of Wisc. 1905;115:171. 